Asha Yathiraj $^{1}$
Gowramma Ittira Poovaiah $^{2^{*}}$

\section{Arithmetic School Readiness of Preschoolers with Hearing Impairment}

Abstract

The study aimed to examine the difficulties of children with hearing impairment in acquiring arithmetic skills at the preschool stage. Two groups of children, one with hearing impairment and another who were typically developing were assessed on a 'Pre-Arithmetic School Readiness Test'. The test that was developed as a part of the current study elicited responses for questions presented through the visual and auditory modality, for questions that required open and closed set responses. The findings of ANOVA, MANOVA and independent $t$-test indicated that the children with hearing impairment performed poorer than the typically developing children in three of the four subcategories of the test (auditory-open, auditory-closed, \& visual-open). The only sub-section where the children with hearing impairment performed better was the visual-closed sub-category. While the children with hearing impairment performed similar to the typically developing children on tasks involving number concepts and shapes, they performed poorer on fundamental operation of addition and subtraction. The test was found to be sensitive to the difficulties of the children with hearing impairment in acquiring arithmetic concepts as it differentiated the performance of the two participant groups.

Keywords: Pre-arithmetic skills, open-set performance, closed-set performanc, number concept, fundamental operation

\section{Introduction}

The importance of early childhood education that includes preschool education has been strongly advocated for all children. Ginsburg (1997) noted that informal concepts formed the prerequisites for formal learning of arithmetic in the later stages of schooling. Likewise, Kaul (2002), based on extensive experience, opined that preschool exposure helps cognitive development of children during primary education and has a strong bearing on attendance and participation once they enter formal school. Policies across Europe (Christopher, 1994) and in the United States of America (Bassok, Fitzpatrick, Loeb, \& Paglayan, 2013; Stipek, 2002) make it a mandate that all children undergo preschool education. Similarly, in India, the Kothari Commission (1966) and the National Policy of Education (1986, amended in 1992) recommends the need and importance of early childhood care and education. Evidence from literature indicates that children with hearing impairment perform poorer in academics compared to their hearing peers (Nunes, 2004; Nunes \& Moreno, 2002; Powers, Gregory, \& Thoutenhoofd, 1999; Swanwick, Oddy, \& Roper, 2005). Besides having difficulties in language, several studies have demonstrated that children with hearing impairment have considerable problems in mathematical abilities (Nunes \& Moreno, 2002; Pagliaro \& Kritzer, 2013; Pau, 1995; Stewart \& Kluwin, 2001; Wood, Wood, \& Howarth, 1983). Stewart and Kluwin (2001) found school-going children with hearing impairment to be underachievers in mathematics. They reported of a disparity in mathematical achievement performance of children with hearing impairment and their hearing counterparts on the Stanford Achievement Test. Although the performance in mathematics of the children with hearing impairment was better than their reading performance, the performance in both areas was below the grade expectancy.

\footnotetext{
${ }^{1}$ Ph.D., Proffessor, All India Institute of Speech and Hearing, Mysore, INDIA. e-mail: asha_yathiraj@rediffmail.com

${ }^{2}$ Ph.D., Associate Proffessor, Regional Institute of Education (National Council of Educational Research and Training), Bhubaneswar, Odisha, INDIA. e-mail: gowriip@yahoo.co.in *Corresponding Author
} 
Similarly, Pau (1995) found that children with hearing impairment studying in primary school had difficulty comprehending verbal mathematical problems. This led to the children having considerable difficulty in arithmetic problem solving. Contrary to studies that reports of children with hearing impairment having difficulty in mathematics, Paranjape (1998) found such children to perform poorer in language but not in mathematics when compared to normal hearing children. These findings were based on the performance of children on achievement tests. However, Paranjape did not indicate whether the performance was grade appropriate or not.

Studies have highlighted that children with hearing impairment often fall behind their hearing peers due to a lack of educational experience during their early years (Gregory, 1998; Nunes, 2004; Nunes \& Moreno, 2002). Exposure to preschool education was found to equip children with hearing impairment for better and successful higher education (Nunes \& Moreno, 1998). Children with hearing impairment, admitted into formal schooling without any prior training, were reported to face difficulty and failure in the school. Hence, it was recommended that they should be prepared prior to getting into formal schooling by undergoing quality preschool education (Nunes \& Moreno, 1998). Mauk and Mauk (1992) considered preschool age to be ideal to identify the problems faced by children with hearing impairment and for corrective measures to be implemented. Studies have also reported of poor preschool experience resulting in reduced mathematical abilities in children with hearing impairment (Nunes \& Moreno, 2002; Pagliaro \& Kritzer, 2013). Nunes and Moreno (2002) noted that many early informal mathematical skills developed prior to formal schooling were not evident in young children with hearing loss. Pagliaro and Klitzer (2013), who examined early mathematics concepts of children with hearing impairment in preschool, reported of strong evidence that their difficulties in mathematics began prior to the start of formal schooling. Pagliaro and Klitzer (2013) also reported that in their participants, the mathematic area of strength was 'geometry' and the areas of weakness were 'problem solving' and 'measurement'.
Thus, it is evident that in children with hearing impairment, difficulties in mathematics commences prior to formal schooling. Hence, it is essential that their specific problems in acquiring early mathematical skills be explored to know the areas of difficulty so that it can be addressed as early as possible. Such assessment would help know the performance level of children and help in making appropriate decisions regarding educational placement, the types of supports required and referral for special educational services. Although this process is important for all children, it is more important for children with hearing impairment. Thus, the present study aimed to develop a school readiness tool and establish its effectiveness in identifying the mathematical difficulties of children with hearing impairment. Audition and vision being the two important modalities used in learning, the study also aimed to evaluate responses through these two modalities using open-set and closed-set questions. Hence, the research questions addressed in the study were:

a. Is there a difference between the acquisition of pre-arithmetic skills at the end of pre-school across children with hearing impairment and typically developing children?

b. Is there a difference in acquiring prearithmetic skills through the visual and auditory modality across children with hearing impairment and typically developing children?

c. Is there a difference in performance on open-set and close-set questions that test pre-arithmetic skills across children with hearing impairment and typically developing children?

d. Can a pre-arithmetic school readiness test detect the specific difficulties of preschool children with hearing impairment?

\section{Method}

The study was carried out in two stages. In the first stage the test material was developed and the second stage dealt with fieldtesting the developed test. The field test was done on typically developing children who had normal hearing and children with hearing impairment.

Participants 
Two groups of participants were included in the study. Group-I consisted of 100 typically developing children without hearing impairment of whom 25 were used for Stage-1 (17 males \& 8 females) of the study and the remaining 75 were used for Stage-II (29 males \& 46 females). Group-II had 37 children with hearing impairment $(20$ males \& 17 females).

The children in Group - I were preschoolers aged $4 \frac{1}{2}$ years to 5 years. For Stage-I of the study, ten children were selected from two regular schools where the instruction was imparted in English and 15 were selected from five regular schools where the instruction was in Kannada, a language spoken in south India. The 75 children selected for Stage-II of the study were from seven schools with English as the language of instruction and five schools with Kannada as the language of instruction. From the former, 40 children and from the latter 35 children were tested on the tool designed for the study. All the schools were located in Mysore city.

The typically developing children had no hearing problem, no history of ear discharge and no other disabilities, as reported by their teachers. The absence of a hearing problem had been confirmed earlier through routine pure-tone screening using Interacoustics PA5 handheld audiometer. Additionally, none of them were reported to have any problem with their school performance. It was ensured that the children selected for the study had been taught in school the mathematical concepts recommended in the syllabus for preschoolers.

The children in Group - II, aged 5 to 6 years, were selected from four special schools, from Mysore and Bangalore, cities in the southern part of India. The children had bilateral severe to profound sensorineural hearing loss, as mentioned in the audiological reports available in the schools. All the children wore for more than two years, binaural behind-the-ear / pseudo-binaural body level hearing aids, prescribed by qualified audiologists. Only those children who were reported to have no additional disability were selected. The children with hearing impairment were reported to have language levels appropriate for the class in which they were studying. All the children had undergone specialized speech and language training and / or special- ized preschool training for approximately one year.

\section{Procedure:}

Stage I: Development of test material

The development of the material involved the following: Compilation of the test materials; validation of test items with professionals and caregivers; and validation of test item on typically developing children.

\section{Compilation of Test Items}

The syllabi for mathematical skills followed in ten regular preschools in and around Mysore were referred since no standard syllabus was available for preschools. The content in the ten syllabi that were common were selected to be included in the test. The compiled test items covered three major areas to assess the arithmetic skills of preschool children. These included number concepts, fundamental operation including concept / application of fundamental operation and shapes. Further, the test material was designed such that the stimuli were presented either auditorily (presented orally) or visually (presented as pictures, written information or objects). This was done to tap the performance of children when the stimuli were presented either through the auditory or visual modality. For the items that were to be tested visually, pictures, written material and objects were compiled. Additionally, the test items were designed to elicit open set responses (where responses were obtained without choices being provided) or closed set responses (where choices were provided for the child to select). Details of the developed test are provided in Table 1. The test material was prepared in English as well as Kannada.

Validation of test items with professionals and caregivers

Validation of the compiled material was done by getting feedback from 35 professionals who dealt with the training of typically developing children / children with hearing impairment. The professionals included ten regular preschool teachers, ten regular primary school teachers, ten special preschool teachers and five speech and hearing professionals. The teachers / professionals were required to indicate whether the concepts as well as the test items were appropriate or not in relation to the syllabus followed by the 
preschools. Additionally, they had to specify if the vocabulary and concepts were age appropriate in both the English and Kannada versions of the test. They also had to indicate whether the two language versions of the test were similar. Modifications and suggestions given by the teachers / professionals were incorporated if more than $10 \%$ of them recommended a change.

Validation of the test items on typically developing children

The developed 'Pre-Arithmetic School Readiness Test' was administered on 25 typically developing children studying in seven different schools. The children were tested individually in the school premises in quiet rooms, free from distraction. They were seated comfortably prior to the commencement of the test. They were instructed orally in Kannada or English, depending on the medium of instruction of the school, regarding what they were expected to do. Breaks were given during the testing, if a child showed any sign of fatigue or restlessness. The children received no feedback as to whether they were right or wrong. Each test item was presented only once. The test items were retained only if more than $80 \%$ of the children responded positively. Using the material that could be carried out by more than $80 \%$ of the children, the test items were finalized. The major task under fundamental operation that had to be eliminated was 'Subtract the object and write the number'. Additionally, the shape 'diamond' had to be removed since many could not identify it.

Stage II: Field testing of the 'Pre-Arithmetic school readiness test'

The developed test was field tested on 75 typically developing children and 37 children with hearing impairment who met the participant selection criteria. Each child was tested independently after being seated comfortably in a distraction free room. The child was seated in front of a table having appropriate height for preschool children. The tester was seated at a distance of 1 meter from the child, on the opposite side of the table on which the test material was placed facing the child.

The instruction for each task was provided orally, one at a time, in the order of the tasks mentioned in Table 1 . The instruc- tions were provided using a vocal effort that is typically used when talking to a person seated 1 meter away. Along with the instruction, the visual material appropriate for the task was placed in front of the child on the table. The instruction for the next task was given only after giving adequate time for the children to complete the previous task. The instruction for a particular task was repeated once, using a constant vocal effort, if a child indicated difficulty in understanding what was said. It was ensured that when a particular task was being evaluated, the child could not view the material for the other tasks. No help was provided by the tester to carry out the tasks. If a child was unable to perform a particular task after the repetition of the instruction, evaluation of the next task was carried out. The children received no feedback as to whether their responses were correct or wrong.

While testing the children with hearing impairment, it was initially established that they wore their prescribed hearing aids that were in working condition. Children who depended on speech-reading were allowed to watch the tester when the instructions were given, in addition to listening. Depending on the task, the responses from the children varied as indicated in Table 1 . The responses, for tasks that required oral or pointing responses from the children, were noted by the tester on a response sheet. Depending on the speed at which a child responded, the test time ranged from 30 minutes to 45 minutes.

The study was carried out adhering to the 'Ethical guidelines for bio-behavioral research involving human subjects' (2009) of the All India Institute of Speech and Hearing, Mysore. Consent of the caregivers was obtained prior to evaluation of the children.

\section{Scoring}

The score for the different test items varied depending on the simplicity of the tasks. In general, a correct response was given score of 1 and an incorrect response a score of 0 . Only two of the tasks ('Count and tick the correct number' \& 'Match the number to number') were assigned a score of 0.5 for a correct answer and 0 for an incorrect answer. Lower scores were assigned to these tasks due the simplicity of the tasks compared to 
Table 1

Details of the "Pre-Arithmetic School Readiness Test"

\begin{tabular}{|c|c|c|c|c|c|c|}
\hline Concepts & Test Tasks & Task description & $\begin{array}{c}\text { Response } \\
\text { mode }\end{array}$ & $\begin{array}{l}\text { No. of } \\
\text { Items }\end{array}$ & $\begin{array}{c}\text { Score per } \\
\text { correct } \\
\text { Response }\end{array}$ & $\begin{array}{c}\text { Maximum } \\
\text { possible } \\
\text { score }\end{array}$ \\
\hline \multirow{10}{*}{ 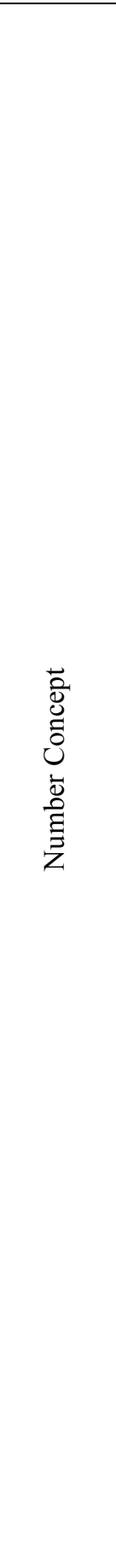 } & $\begin{array}{l}\text { 1. Count \& } \\
\text { write }\end{array}$ & $\begin{array}{l}\text { Pictures of familiar objects are } \\
\text { shown and the child is required } \\
\text { to count and write the number } \\
\text { of objects. }\end{array}$ & VO & 5 & 1 & 5 \\
\hline & $\begin{array}{l}\text { 2. Count \& } \\
\text { tick the } \\
\text { correct } \\
\text { number }\end{array}$ & $\begin{array}{l}\text { Pictures of familiar objects are } \\
\text { shown and the child is required } \\
\text { to count and point/tick the } \\
\text { number of objects from the } \\
\text { given written choices. }\end{array}$ & VC & 5 & 0.5 & 2.5 \\
\hline & $\begin{array}{l}\text { 3. Write } \\
\text { the missing } \\
\text { number } \\
\text { (Before) }\end{array}$ & $\begin{array}{l}\text { A written number is provided } \\
\text { with a blank space before and } \\
\text { after it. The child is expected } \\
\text { to fill in the blank with a num- } \\
\text { ber that comes prior to the } \\
\text { written one. }\end{array}$ & VO & 5 & 1 & 5 \\
\hline & $\begin{array}{l}\text { 4. Write } \\
\text { the missing } \\
\text { number } \\
\text { (After) }\end{array}$ & $\begin{array}{l}\text { A written number is provided } \\
\text { with a blank space before and } \\
\text { after it. The child is expected } \\
\text { to fill in the blank with a num- } \\
\text { ber that comes after the writ- } \\
\text { ten one. }\end{array}$ & VO & 5 & 1 & 5 \\
\hline & $\begin{array}{l}\text { 5. Listen } \\
\text { and an- } \\
\text { swer the } \\
\text { statement } \\
\text { (before) }\end{array}$ & $\begin{array}{l}\text { To the oral command of the } \\
\text { tester, the child has say what } \\
\text { number comes before a partic- } \\
\text { ular number. }\end{array}$ & $\mathrm{AO}$ & 5 & 1 & 5 \\
\hline & $\begin{array}{l}\text { 6. Listen } \\
\text { and an- } \\
\text { swer the } \\
\text { statement } \\
\text { (after) }\end{array}$ & $\begin{array}{l}\text { To the oral command of the } \\
\text { tester, the child has to say } \\
\text { what number comes after a } \\
\text { particular number. }\end{array}$ & $\mathrm{AO}$ & 5 & 1 & 5 \\
\hline & $\begin{array}{l}\text { 7. Match } \\
\text { the digits }\end{array}$ & $\begin{array}{l}\text { Two columns of numbers (dig- } \\
\text { its) are shown. The child is } \\
\text { expected to match the num- } \\
\text { bers in the two columns. }\end{array}$ & VC & 5 & 0.5 & 2.5 \\
\hline & $\begin{array}{l}\text { 8. Match } \\
\text { the digit } \\
\text { and word } \\
\text { numbers }\end{array}$ & $\begin{array}{l}\text { Two columns of numbers, one } \\
\text { with digits and the other with } \\
\text { the same numbers in words are } \\
\text { shown. The child is expected } \\
\text { to match the numbers. }\end{array}$ & VC & 5 & 1 & 5 \\
\hline & $\begin{array}{l}\text { 9. Listen } \\
\text { and point } \\
\text { at the } \\
\text { number }\end{array}$ & $\begin{array}{l}\text { Five numbers (digits) are } \\
\text { shown. The child is required to } \\
\text { point to the number said by } \\
\text { the tester. }\end{array}$ & $A C$ & 5 & 1 & 5 \\
\hline & $\begin{array}{l}\text { 10. Listen } \\
\text { and point } \\
\text { to the } \\
\text { word }\end{array}$ & $\begin{array}{l}\text { Five numbers (words) are } \\
\text { shown. The child is required to } \\
\text { point to the number said by } \\
\text { the tester. }\end{array}$ & $\mathrm{AC}$ & 5 & 1 & 5 \\
\hline
\end{tabular}


(Table 1 continued)

1. Add the objects and write the number

3. Auditory (statement problems)

4. Auditory (statement problems)

\section{(statement} problems

Subtraction (statement problems)

2. Auditory (statement problems)

3. Subtraction (statement problems) 1. Color the
shapes

2. Name the

shapes

3. Show the correct shapes

4. Draw the following
Two groups of objects are shown with the symbol ' + ' between them. The child is required to add the two groups and write the answer.

The child is shown two sets of objects and is provided simple instructions such as "I have 2 pens, mother gave me 2 more. How many do 1 have now"? The child is required to point to the 2 written choices given, one correct and the other wrong.

The child listens to simple statement problems regarding addition, with no visual clues and no options provided. A verbal response is required.

The child listens to simple statement problems regarding addition, with no visual clues but with 2 written options provided. The child points to one of the choices provided.

The child is shown two sets of objects and is provided simple instructions such as "I have 6 chocolates. I gave 2 chocolates. Do I have 4 or 3 chocolates remaining with me"? The child has to point to two written choices given.

The child listens to simple statement problems regarding subtraction, with no visual clues and no options provided. A verbal response is required.

The child listens to simple statement problems regarding subtraction, with no visual clues but with 2 written options provided. The child points to the choices provided.

From a choice of four line drawings of shapes shown, the child is required to color the one mentioned in a written instruction.

The child is required to name the line drawing of a shape shown.

The child is expected to show a shape said by the tester from a choice of four line drawing options presented.

\begin{tabular}{l|l|l|l|l} 
& $\begin{array}{l}\text { 4. Draw the } \\
\text { following }\end{array}$ & $\begin{array}{l}\text { The child is required to draw the } \\
\text { shape said by the tester. }\end{array}$ & 4 & 4 \\
\hline $\begin{array}{l}\text { Total } \\
\text { items } \\
\text { marks }\end{array}$ & & & & \\
\hline
\end{tabular}

Note. Total score for: Visual open $(V O)=24 ;$ Visual closed $(V C)=24 ;$ Auditory open $(A O)=24$; Auditory closed $(A C)=24$

VO

$\begin{array}{llll}V C & 4 & 1 & 4\end{array}$

$\begin{array}{llll}\text { VO } & 4 & 1 & 4\end{array}$

$\begin{array}{llll}A C & 4 & 1 & 4\end{array}$

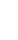


the other tasks. Details regarding the scores to be assigned to the different tasks are provided in Table 1. The total possible score for the 101 items was 96.

\section{Results}

The data were analyzed using SPSS (version 17) to compare the performance of the typical developing children with children with hearing impairment on the following: types of questions (open and closed) and questions tapping two sensory modalities (auditory and visual). Further, the performance of the children on the two types of questions and questions tapping two sensory modalities were also compared within each participant group. The data of all 100 typically developing children were analyzed after scoring only those questions that were selected in the final test.
The data were analyzed using repeated measure ANOVA, MANOVA and independent t-test. A Mann-Whitney test was used to confirm the results of the parametric statistics between the participant groups, as the sample size differed considerably.

I. Comparison of scores between participant groups (typically developing children and children with hearing impairment)

The mean and standard deviation (SD) of the overall performance of typically developing children with children with hearing impairment is depicted in Table 2 . It can be seen that the mean score of the typically developing children was higher than that obtained by the children with hearing impairment. Similarly, the SD was lesser in the typically developing group compared to the group with hearing impairment.

Table 2.

Mean and SD of the total test scores of the two groups

\begin{tabular}{ccccccc}
\hline Groups & N & \#Mean & SD & $\begin{array}{c}\text { Lower } \\
\text { bound }\end{array}$ & $\begin{array}{c}\text { Upper } \\
\text { bound }\end{array}$ & t value \\
\hline Typically developing & 100 & 92.6 & 4.32 & 77 & 96 & $6.38^{* *}$ \\
\hline Hearing impaired & 37 & 84.84 & 9.98 & 56 & 96 & \\
\hline Note. \# Maximum possible score $=96$ & & & &
\end{tabular}

$$
* *=p<0.01
$$

A two-tailed independent $t$-test was performed to check if the difference in scores was significant. The $t$-test indicated that there was a statistically significant difference between the typically developing children and the children with hearing impairment $t ~(135)$ $=6.38, p<0.01]$ for the overall scores. Since the sample size of the two groups was unequal, the result of the independent $t$-test was cross-checked with a non-parametric MannWhitney test. Similar results were obtained through both the statistical procedures $(z=$ $4.67, p<0.01$ ).

Comparison of the mean and SD of the scores obtained for questions tapping table it is evident that for the visual based questions the mean scores were almost similar with not much variation in SD between the two groups. In contrast, for the auditory based questions there was a marked difference in the mean scores between the two groups. The SD was considerably more for the children with hearing impairment compared to the typically developing children. visual and auditory modalities (with types of questions combined) by the two groups of children can be seen in Table 3. From the

In order to determine how the two participant groups differed from each other for the visual and auditory based question, a MANOVA test was conducted. It revealed that there was a significant difference between the typically developing children and the children with hearing impairment for questions tapping the auditory modality $[F(1$, 135) $=53.93, p<0.01$, partial $\left.\eta^{2}=.29\right]$.

In contrast, no such difference between the participant groups was seen for the visual based questions $[F(1,135)=1.974$, $p>0.05$, partial $\eta^{2}=.02$ ]. The non-parametric tests also showed a significant difference 
Table 3.

Mean and SD of the scores for the modalities (visual \& auditory) and type of questions (open \& closed) for the two groups

\begin{tabular}{|c|c|c|c|c|c|c|c|c|}
\hline & & Groups & $\mathbf{N}$ & \#Mean & SD & $\begin{array}{l}\text { Lower } \\
\text { bound }\end{array}$ & $\begin{array}{l}\text { Upper } \\
\text { bound }\end{array}$ & $\begin{array}{c}\mathbf{z} \\
\text { values }\end{array}$ \\
\hline \multirow{4}{*}{ Modality } & \multirow[t]{2}{*}{ Visual } & Typically developing & 100 & 47.63 & 1.32 & 47 & 48 & \multirow[t]{2}{*}{0.51} \\
\hline & & Hearing impaired & 37 & 47.16 & 2.53 & 47 & 48 & \\
\hline & \multirow[t]{2}{*}{ Auditory } & Typically developing & 100 & 45.03 & 3.76 & 44 & 46 & \multirow[t]{2}{*}{$5.09 * *$} \\
\hline & & Hearing impaired & 37 & 37.43 & 8.34 & 36 & 39 & \\
\hline \multirow{4}{*}{$\begin{array}{l}\text { Question } \\
\text { type }\end{array}$} & \multirow[t]{2}{*}{ Open } & Typically developing & 100 & 46.65 & 1.84 & 41 & 48 & \multirow[t]{2}{*}{$-5.18 * *$} \\
\hline & & Hearing impaired & 37 & 41.72 & 6.65 & 18 & 48 & \\
\hline & \multirow[t]{2}{*}{ Closed } & Typically developing & 100 & 46.04 & 2.90 & 33 & 48 & \multirow[t]{2}{*}{$-4.42 * *$} \\
\hline & & Hearing impaired & 37 & 42.83 & 3.95 & 38 & 48 & \\
\hline
\end{tabular}

Note. \# Maximum possible score $=48$

$$
* *=p<0.01
$$

between the groups for the auditory based questions $(z=5.09, p<0.01)$ but not for the visual based questions $(z=0.51, p>0.05)$. A comparison of scores for open and closed type of questions (with modalities combined), for the two groups, indicated that the performance was similar to the earlier analyses. The performance of the typically developing children was better than that of children with hearing impairment for the open as well as the closed type of questions. Likewise, the SD was more for the children with hearing impairment in both the types of questions. This can be observed from the mean and SD provided in Table 3.

To compare the scores of the open and closed type of questions, a MANOVA test was carried out. A significant difference was seen between the two groups for the open $[$ Wilks' $\Lambda=.74, F(1,135)=45.73, p<0.01$, partial $\eta^{2}=.25$ ] and closed [Wilks' $\Lambda=.74, F(1$, $135)=26.88, p<0.01$, partial $\eta^{2}=.17$ ] type of questions.
Similar findings were obtained using a MannWhitney test where there was a significant difference between the two groups for the open $(z=-5.18, p<0.01)$ and closed type of questions $(z=-4.42, p<0.01)$.

Comparison of stimuli [question type (open \& closed) \& modality (visual \& auditory)] across participant groups was performed using a MANOVA. Additionally, the MANOVA output for the 4 variables (visual closed, visual open, auditory open, auditory closed) was cross checked with a Mann-Whitney test.

From Table 4 it can be observed that the typically developing children and the children with hearing impairment performed differently. The former group performed significantly differently on open and closed type of questions when they were visual based. However, in the latter group, this difference was not seen for the visual based tasks but was seen for the auditory based tasks.

Table 4.

Mean, SD and $p$ values for responses to visual open, visual closed, auditory open and auditory closed questions for the two group

\begin{tabular}{|c|c|c|c|c|c|c|c|}
\hline \multirow{2}{*}{ Type of question/ modality } & \multirow{2}{*}{$\begin{array}{l}\text { Participant } \\
\text { groups }\end{array}$} & \multirow{2}{*}{$\mathbf{N}$} & \multirow{2}{*}{$\begin{array}{c}\# \\
\text { Mean }\end{array}$} & \multirow{2}{*}{ SD } & \multicolumn{2}{|c|}{ Parametric Stat } & \multirow{2}{*}{$\begin{array}{c}\text { Non-parametric Stat } \\
\mathrm{Z}\end{array}$} \\
\hline & & & & & $\mathbf{F}$ & df & \\
\hline \multirow[t]{2}{*}{ Visual open } & $\begin{array}{l}\text { Typically } \\
\text { developing }\end{array}$ & 100 & 23.92 & 0.46 & \multirow[t]{2}{*}{8.30} & \multirow[t]{2}{*}{$135^{* *}$} & \multirow[t]{2}{*}{$-2.06 * *$} \\
\hline & Hearing impaired & 37 & 23.16 & 2.53 & & & \\
\hline \multirow[t]{2}{*}{ Visual closed } & $\begin{array}{l}\text { Typically } \\
\text { developing }\end{array}$ & 100 & 23.71 & 1.14 & \multirow[t]{2}{*}{2.39} & \multirow[t]{2}{*}{135} & \multirow[t]{2}{*}{-1.77} \\
\hline & Hearing impaired & 37 & 24.00 & .000 & & & \\
\hline \multirow[t]{2}{*}{ Auditory open } & $\begin{array}{l}\text { Typically } \\
\text { developing }\end{array}$ & 100 & 22.73 & 1.77 & \multirow[t]{2}{*}{55.96} & \multirow[t]{2}{*}{$135^{* *}$} & \multirow[t]{2}{*}{$-5.32 * *$} \\
\hline & Hearing impaired & 37 & 18.76 & 4.77 & & & \\
\hline \multirow[t]{2}{*}{ Auditory closed } & $\begin{array}{l}\text { Typically } \\
\text { developing }\end{array}$ & 100 & 22.30 & 2.30 & \multirow[t]{2}{*}{39.64} & \multirow[t]{2}{*}{$135 * *$} & \multirow[t]{2}{*}{$-4.77 * *$} \\
\hline & Hearing impaired & 37 & 18.86 & 3.95 & & & \\
\hline
\end{tabular}

Note. \# Maximum possible score $=24$

$* *=p<0.01$ 


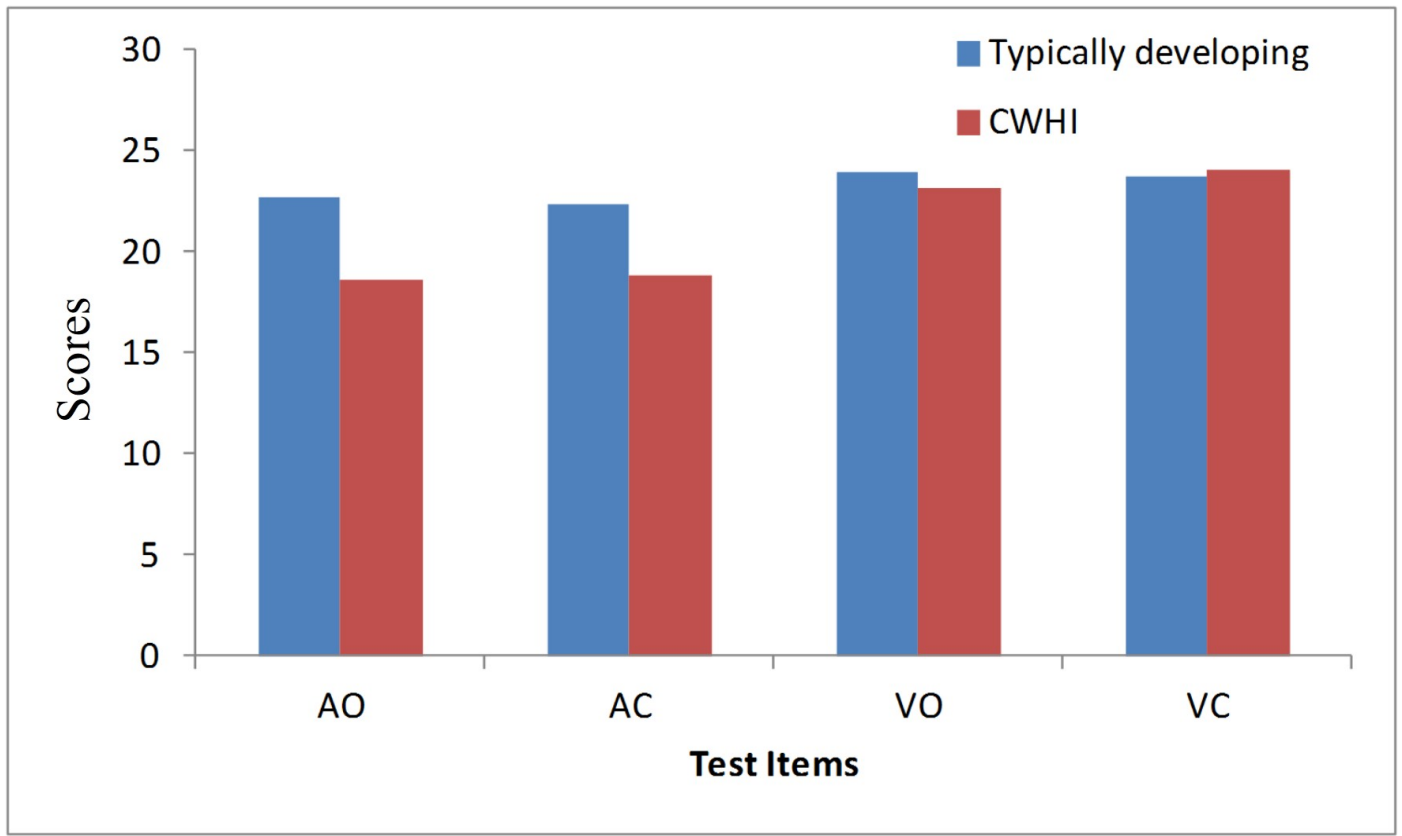

Figure 1.

Performance of typically developing children and children with hearing impairment (CWHI) for the auditory open (AO), auditory closed (AC), visual open (VO) and visual closed (VC) stimuli.

It is clear from Figure 1 that between the two groups there was a marked difference in scores for the auditory based questions.
This marked difference was not present for the visual based items.

Table 5.

Summary of the comparison between typically developing children and children with hearing impairment (CWHI) for different stimuli

\begin{tabular}{llllllllll}
\hline & $\begin{array}{l}\text { Total } \\
\text { score }\end{array}$ & VO+VC & AO+AC & VO+AO & VC+AC & VO & VC & AO & AC \\
\hline $\begin{array}{l}\text { Typically } \\
\begin{array}{l}\text { Developing } \\
\text { Vs CWHI }\end{array}\end{array}$ & $p<0.01$ & $p>0.05$ & $p<0.01$ & $p<0.01$ & $p<0.01$ & $p<0.01$ & $p>0.05$ & $p<0.01$ & $p<0.01$ \\
\hline
\end{tabular}

Note. $V O=$ Visual open; $V C=$ Visual closed $; A O=$ Auditory open $A C=$ Auditory closed

The two groups did not differ only for the visual based tasks, especially for the closed type of questions (Table 5). For all the auditory based tasks, there was a significant difference between the two groups.

II. Comparison of scores within participant groups (typically developing children and children with hearing impairment)

To determine whether there existed any significant difference between scores for type of questions (open \& closed) and modality (auditory \& visual), a repeated measure ANOVA was carried out within each of the participant groups. With the type (open \& closed) and modality (auditory \& visual) combined, there was a significant main effect for the typically developing children [Wilks' $\Lambda=.64, F(1,99)=$ 54.85, $p<0.01$, partial $\eta^{2}=.36$ ] as well as for the children with hearing impairment

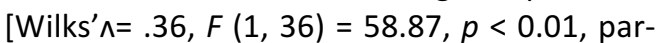
tial $\left.\eta^{2}=.62\right]$. Since there was a significant main effect, a $t$-test was carried out to check the performance in type and modalities for each of the participant groups.

The t-test results indicated that for the visual and auditory based questions in the typically developing group (Table 6) there was a significant difference for the visual and auditory tasks. When the visual and auditory questions were sub-categorized as open and closed, the performance differed. For the visual tasks, no significant difference was seen between the open and closed question 
$(p>0.05)$. On the other hand, for the auditory based question there was a significant difference for the open and closed type of questions.

In the group of children with hearing impairment there was a significant difference between the total visual and auditory task as well as the visual open and the visual closed task $(p<0.01)$.
However, no significant difference was seen for the auditory open and auditory closed tasks $(p>0.05)$.

A comparison of scores of the open and closed type of questions within each group (Table 6) using a $t$-test indicated the two types of questions were significantly different. This was seen for the total scores of the open and closed type of questions as well as for the visual based and auditory based question in both participant groups.

Table 6.

Comparison of open and closed type of questions for visual and auditory based questions as well as visual and auditory based questions for open and closed type of questions in typically developing children and children with hearing impairment (CWHI).

\begin{tabular}{|c|c|c|c|c|c|}
\hline Groups & Modalities \& Type of Questions & Mean & SD & df & $\mathbf{t}$ \\
\hline \multirow{6}{*}{$\begin{array}{l}\text { Typically de- } \\
\text { veloping }\end{array}$} & Visual total scores \# & 47.63 & 1.32 & \multirow[b]{2}{*}{99} & \multirow{2}{*}{$7.15^{* *}$} \\
\hline & Auditory total scores \# & 45.03 & 3.76 & & \\
\hline & Visual open scores \#\# & 23.92 & 0.46 & \multirow{2}{*}{99} & \multirow{2}{*}{1.86} \\
\hline & Visual closed scores \#\# & 23.71 & 1.14 & & \\
\hline & Auditory open scores \#\# & 22.73 & 1.77 & \multirow{2}{*}{99} & \multirow{2}{*}{$2.60 * *$} \\
\hline & Auditory closed scores \#\# & 22.30 & 2.30 & & \\
\hline \multirow{6}{*}{ CWHI } & Visual total scores \# & 47.16 & 2.53 & \multirow{2}{*}{36} & \multirow{2}{*}{$8.02 * *$} \\
\hline & Auditory total scores \# & 37.43 & 8.34 & & \\
\hline & Visual open scores \#\# & 23.16 & 2.53 & \multirow{2}{*}{36} & \multirow{2}{*}{$2.01^{*}$} \\
\hline & Visual closed scores \#\# & 24.00 & .000 & & \\
\hline & Auditory open scores & 18.76 & 4.77 & \multirow{2}{*}{36} & \multirow{2}{*}{0.68} \\
\hline & Auditory closed scores \#\# & 18.86 & 3.95 & & \\
\hline \multirow{6}{*}{$\begin{array}{l}\text { Typically de- } \\
\text { veloping }\end{array}$} & Open total scores \# & 46.65 & 1.84 & \multirow{2}{*}{99} & \multirow{2}{*}{$2.63^{* *}$} \\
\hline & Closed total scores \# & 46.04 & 2.90 & & \\
\hline & Open visual scores \#\# & 23.92 & 0.46 & \multirow{2}{*}{99} & \multirow{2}{*}{$6.56 * *$} \\
\hline & Open auditory scores \#\# & 22.73 & 1.77 & & \\
\hline & Closed visual scores \#\# & 23.71 & 1.14 & \multirow{2}{*}{99} & \multirow{2}{*}{$6.70^{* *}$} \\
\hline & Closed auditory scores \#\# & 22.30 & 2.30 & & \\
\hline \multirow{6}{*}{ CWHI } & Open total scores \# & 41.72 & 6.65 & \multirow{2}{*}{36} & \multirow{2}{*}{$1.24 * *$} \\
\hline & Closed total scores \# & 42.83 & 3.95 & & \\
\hline & Open visual scores \#\# & 23.16 & 2.53 & \multirow{2}{*}{36} & \multirow{2}{*}{$7.49 * *$} \\
\hline & Open auditory scores \#\# & 18.76 & 4.77 & & \\
\hline & Closed visual \#\# & 24.00 & .000 & \multirow{2}{*}{36} & \multirow{2}{*}{$7.92^{* *}$} \\
\hline & Closed auditory scores \#\# & 18.86 & 3.95 & & \\
\hline
\end{tabular}

Note. Visual total = Visual open + Visual closed;

Auditory total = Auditory open + Auditory closed;

Open total = Open visual + Open auditory;

Closed total = Closed visual + Closed auditory

\# Maximum possible score $=48$;

\#\# Maximum possible score $=24$;

$* *=p<0.01$

III. Comparison of scores on specific mathedeveloping group and the group with hearing impairment for number concept $[F(1,135)=$ 3.06, $p>0.05$, partial $\left.\eta^{2}=.02\right]$ and knowledge of shapes $[F(1,135)=1.00, p>0.05$, partial $\left.\eta^{2}=.01\right]$. However, the children with hearing impairment performed significantly poorer 
than their typically developing counterparts on the two fundamental operations that were evaluated, addition $[F(1,135)=31.84, p<$ 0.001 , partial $\left.\eta^{2}=.19\right]$ and subtraction $[F(1$, $135)=58.64, p<0.001$, partial $\eta^{2}=.3$ ]. Due to the unequal sample size in the two participant groups, the results were verified using a non-parametric statistical test. Similar to what was observed with the parametric test, the Mann-Whitney test highlighted that a significant different between the groups for 'number concept' $(z=-.522, p>0.05)$ and knowledge of shapes $(z=-1.06, p>0.05)$ was absent, but was present for fundamental operations of addition $(z=-4.410, p<0.001)$ and subtraction $(z=-5.4, p<0.001)$.

To establish whether extraneous factors such as the school in which the children studied and the medium of instruction had an impact of the performance of the children with hearing impairment, further analyses were carried out. A Kruskal-Wallis test was performed to determine whether there was a significant difference between the 4 special schools ( 2 in Mysore \& 2 in Bangalore) and the 2 mediums of instruction (English \& Kannada).
From the findings of the Kruskal-Wallis test, no significant difference was observed between the four different special schools, $\left[\chi^{2}(3\right.$, $N=37)=2.5, p>0.05$ ] as well as the 2 languages $\left(\chi^{2}(1, N=37)=0.39, p>0.05\right)$.

IV. Reliability of the Pre-Arithmetic School Readiness Test

The reliability of the pre-arithmetic school readiness test was checked by computing Cronbach's $\alpha$ separately for each of the participant groups. This was done separately for visual open scores, visual closed scores, auditory open scores, auditory closed scores as well as for the overall test scores. From Table 7 it can be seen that the Cronbach's $\alpha$ values ranged from .83 to .90 in the typically developing children and ranged from .88 to 1 in the children with hearing impairment. These results confirm that the pre-arithmetic school readiness test has high reliability irrespective of whether it is administered on typically developing children or on children with hearing impairment.

Table 7.

Reliability of the pre-arithmetic school readiness test on typically developing children and children with hearing impairment.

Cronbach's Alpha

\begin{tabular}{lcc} 
& $\begin{array}{c}\text { Typically developing } \\
\text { children }\end{array}$ & $\begin{array}{c}\text { Children with hearing } \\
\text { impairment }\end{array}$ \\
\hline Visual open & .90 & .93 \\
Visual closed & .89 & 1.0 \\
Auditory open & .86 & .88 \\
Auditory closed & .83 & .90 \\
Overall & .84 & .90 \\
\hline
\end{tabular}

\section{Discussion}

From the comparison of performance between the two groups of children it is evident that the typically developing children performed significantly better than the children with hearing impairment. This was seen for the overall scores and for all the auditory based questions. This higher score for the auditory based questions was seen for the total auditory based score as well as when the questions were sub-categorized as audi- tory open and auditory closed. In both groups the scores dropped for the auditory based questions, but this drop was more prominent for the children with hearing impairment. This is evident from the mean scores provided in Table 5.

Similar observations were made in earlier studies by Pau (1995) and Wood et al., (1983), Nunes and Moreno (2002), Swanwick et al. (2005). They too observed that children with hearing impairment performed poorer than typically developing children on the 
tasks evaluated by them. Their participants faced difficulty despite the evaluation being done using written tests. Contrary to the above findings, Traxler (2000) observed children with hearing impairment to perform on par with their counterparts who had normal hearing. However, this finding was attributed to the purposive sampling of students who performed well. Hence, their findings cannot be generalized to all students with hearing impairment. Similar to the findings of Traxler, it was reported by Paranjape (1998) that children with hearing impairment could perform like typically developing children. This latter study however, made no mention if the tasks evaluated were grade appropriate. Despite the drawbacks of the studies by Traxler as well as Paranjape, their findings highlight that certain children with hearing impairment are capable of performing on par with their typically developing peers.

In the current study, in contrast to the performance on the auditory based questions, the total score on the visual based questions were not significantly different in the two groups. This suggests that all children in the early stages of their development are dependent more on the visual modality for concept formation even if the auditory modality is fully functional. There continued to be no significant difference between the two groups when the visual based questions were given with choices of answers (closed type). On the other hand, when the visual based questions were given with no choices (open type), there was a significant difference between the two groups. On the visual-closed task, the children with hearing impairment preformed slightly better than the typically developing children (Table 4, Figure 1, \& Table 6). This indicates that on visual based tasks with options given, children with hearing impairment are able to perform at par with typically developing children but not when options were absent.

In consonance with the findings of the present study, Nunes and Moreno (2002) reported of improved performance of children with hearing impairment with the use of visual representation of the problems. Likewise, children with hearing impairment were found to outperform the young children in informal spatial pre-arithmetic tasks by Zarfaty, Nunes and Bryant (2004). As early as 1971, Erber reported that children with hear- ing impairment relied on visual cues for comprehension in spite of amplified acoustic cues being provided. This trend continues to be present despite the advances in technology resulting in children with hearing impairment using digital technology that is expected to reduce their dependence on visual cues. This highlights the need to stress on providing listening training for children with hearing impairment. This would help them cope in a regular school set-up where major mode of learning is through the auditory modality. Additionally, the use of more visual instruction in the regular classroom, where children with and study together, would be beneficial.

The findings of the present study indicate that when visual-closed questions are used, a ceiling effect was seen in both groups, resulting in no significant difference between the groups. Although the children with hearing impairment obtained similar mean scores for the visual-open and the visual-closed type of questions, the variability was larger for the former. The latter resulted in the participants obtaining perfect scores, thus resulting in no variability. This probably led to the significant difference between the groups only for the visual-open type of questions. Wilson and Antablin (1980) also observed that closed-set speech identification abilities in individuals with hearing impairment were far better than their open-set responses. Additionally, they noted that individuals with hearing impairment did not achieve $100 \%$ open-set word perception even when the material was presented at sufficient loudness.

The performance of the children on specific mathematical concepts revealed that children with hearing impairment had significantly more difficulty than the typically developing children in fundamental operations involving addition and subtraction, but not in number concept and shapes. This indicates that they have difficulty in grasping arithmetic concepts that are relatively more complex but are on par with the typically developing children on tasks that are less complex (number concept) or that can be easily grasped using visual cues (shapes). It is possible that the inability to use the auditory mechanism to the same extent as normal hearing children could have prevented them from grasping arithmetic concepts within and outside the classroom. 
Hyde, Zevenbergen, and Power (2003) also reported of older children with hearing impairment, studying in grades 1 to 12 , having difficulty in the use of analytical and thinking strategies to solve arithmetic word problems. Additionally, Epstein et al. (1994) found that limited auditory experience effecting short-term memory, was a factor for poor performance of college students with hearing impairment. Recently, Gowramma (2014) also reported that children with hearing impairment had more difficulty in carrying out fundamental operations that required higher order thinking. It was found that children with hearing impairment studying in grades 4 and 5 performed similar to their hearing peers in addition and subtraction, but performed poorer in multiplication and division. It was concluded that mathematical reasoning in children with hearing impairment was on par with hearing children but the learning process was slow. Similar observations were made by Meadow-Orlans (1980).

Swanwick et al. (2005) reported that findings from research studies between 1980 -2000 suggest that there is an average delay of 2 to 3.5 years in mathematical achievement in children with hearing loss. However, many of these children were reported to show similar processes as their hearing peers, confirming the suggestion of delay in mathematical development rather than a disorder or deviant development. Based on the above study, Swanwick et al. (2005) suggested that students functioning at lower mathematic levels may not have the opportunity to be exposed to the curriculum content at a higher level and therefore continue to perform poorly in content that requires the use of higher order analytical skills.

The presence of a hearing impairment and the ensuing cognitive problem could have hampered incidental learning that takes place in typically developing children outside the classroom. This has also been reported by Kritzer (2009) who suggested that a lack of incidental learning experiences could have led to the participants with hearing impairment aged 4 to 6 performing poorly on informal mathematical problems including word problems. The finding of the current study suggests that children with hearing impairment are unable to utilize this channel of learning. Further, factors such as school and medium of instruction were found to have no influence on the performance of children with hearing impairment. Thus, studies reported in literature indicate that in individuals with hearing impairment, higher cognitive factors influence arithmetic performance. From the findings of the current study and that reported in the literature, it can be construed that the difficulties in using higher cognitive functions in fundamental operations of arithmetic is present right at the initial formative ages and continues to persists later in life while solving word problems. Hence, the focus of intervention should be more towards compensating for the auditory input. As children with hearing impairment were able to utilize visual cues better than auditory cues (Table 4 \& Figure 1 ), it is recommended that more visual based activities be used in preschools in order enable these children grasp such concepts. Training to make fundamental operations clear to children with hearing impairment should be incorporated in the teaching-learning process right from the preschool age. This could reduce the difficulties faced by them in arithmetic in higher classes.

From the findings of the present study, it can be inferred that the newly developed pre-arithmetic school readiness test that has high reliability is sensitive to detect the specific difficulties children with hearing impairment have in learning arithmetical concepts. This would enable planning appropriate remedial instruction for children with hearing impairment. The test can also be used as a guideline to decide on educational placement of such children by special educators or speech and hearing professionals. The developed test also could also be used as a tool to demonstrate to caregivers of children with hearing impairment regarding the importance of providing their wards training prior to admission to school. Narayansamy, Ramkumar, and Nagarajan (2014) noted that mother of children with hearing impairment in rural south India believed that once children with hearing impairment were fitted with hearing aids they could go to regular schools without further intervention. Tests such as the 'Pre-arithmetic school readiness tool' could be utilized to highlight to them the need for special intervention to prepare their children for regular school. Further, the developed test not only throws light on the 
arithmetic performance of children with hearing impairment, but also on the performance of typically developing children.

\section{Conclusions}

The comparison of performance of the two groups (typically developing \& children with hearing impairment) for the sensory modality (visual \& auditory) and type of questions (open \& closed), revealed a statistically significant difference. This difference was seen for the scores of auditory stimuli, open type of questions and closed type of questions. However, the performance of the two groups did not differ significantly for the visual based stimuli. Within the visual based tasks, the two participant groups did not differ significantly for the closed type of questions but did for the open type. When the scores were compared within each of the participant groups, the pattern of difficulty varied for the categories studied. This indicated that the level of difficulty varied depending on whether they had hearing impairment or not. Further, children with hearing impairment performed at par with typically developing children on tasks such as number concepts and shapes. On the other hand, they performed poorer than the typically developing children on fundamental operation of addition and subtraction.

Thus, it can be construed from the finding of the present study that though children with hearing impairment wear state-ofthe-art hearing devices to compensate for their hearing loss, they continue to have difficulty in carrying out auditory based activities. Hence, while planning auditory based activities, special care is required to make the signals audible to the children with hearing impairment. Additionally, intensive listening training is recommended to enhance their listening skills. This along with the use of visual representation of the mathematical problems would enhance learning of mathematics in these children in their early years of development.

The study provides insight to the specific strengths and weaknesses of young children with hearing impairment in mathematics. The 'pre-arithmetic school readiness test' was found to be sensitive in tapping the difficult areas of pre-arithmetical concepts in children with hearing impairment. Such tests would help in planning appropriate remedial instruction programs for children with hearing impairment and in selecting educational placement. However, the present study is limited to only one regional language. It is recommended that similar tests be developed and validated in other languages.

\section{Acknowledgement}

The authors thank the All India Institute of Speech and Hearing, Mysore, for providing the financial assistance to carry out the study. The assistance of Ms. Prithi Nair and Ms. Vijetha P. while compiling the test items, Mr. Varun A. with data collection, Dr. Vasantha Lakshmi and Mr. Akshay R. Maggu for statistical analysis is appreciated.

\section{Funding}

This original study was wholly funded by the All India Institute of Speech and Hearing research fund (SH/CDN/ARF/3.50/AY/2009-10) of All India Institute of Speech and Hearing, Mysuru, India

\section{References}

Bassok, D., Fitzpatrick, M., Loeb, S., \& Paglayan, S. (2013). The early childhood care and education workforce in the United States: Understanding changes from 1990 through 2010. Education Finance and Policy, 8(4), 581-601. doi: 10.1162/EDFP_a_00114

Christopher, B. (1994). Start right: The importance of early learning. London (England): Royal Society for the Encouragement of Arts, Manufactures, and Commerce

Epstein, I., Hillegeist, G., \& Grafman, J. (1994). Number processing in deaf college students. American Annals of the Deaf, 139(3), 336-347. doi: $10.1353 /$ aad.2012.0321

Erber, P. (1975). Auditory-visual perception of speech. Journal of Speech and Hearing Disorders, 40(4), 481-492. doi: doi:10.1044/jshd.4004.481

Ethical Guidelines for Bio-Behavioural Research Involving Human Subjects. 
(2009). Mysore, India: All India Institute of Speech and Hearing.

Ginsburg, P. (1997). Mathematics learning disabilities: A view from developmental psychology. Journal of Learning Disabilities, 30(1), 20-33. doi: 10.1177/002221949703000102

Gowramma, P. (2014). Arithmetic difficulties of children with hearing impairment In S. Chinn (Ed.), Routeledge international handbooks: The routeledge international handbook of dyscalculia and mathematical learning difficulties. UK: Taylor \& Francis.

Gregory, S. (1998). Mathematics and deaf children. In S. Gregory, P. Knight, W. Mccracken, S. Powers \& L. Watson (Eds.), Issues in Deaf Education. London: Faulton press.

Hyde, M., Zevenbergen, R., \& Power, J. (2003). Deaf and hard of hearing students' performance on arithmetic word problems. American Annals of the Deaf, 148(1), 56-64. doi: 10.1353/aad.2003.0003

Kaul, V. (2002). Early childhood care and education. In R. Govinda (Ed.), India Education Report. New Delhi: Oxford University Press.

Kothari commission report. (1966). Education and National Development: Report of the Education Commission 196466. New Delhi: Retrieved from http://www.teindia.nic.in/Files/Repo rts/CCR/KC/KC_V1.pdf.

Kritzer, L. (2009). Barely started and already left behind: A descriptive analysis of the mathematics ability demonstrated by young deaf children. Journal of Deaf Studies and Deaf Education, 14(4), 409-421.

Mauk, W., \& Mauk, P. (1992). Somewhere, out there: Preschool children with hearing impairment and learning disabilities. Topics in Early Childhood Special Education, 12(2), 174-195. doi: 10.1177/027112149201200204

Meadow-Orlans, P. (1980). Deafness and child development. California: University of California Press.

Narayansamy, M., Ramkumar, V., \& Nagarajan, R. (2014). Knowledge and Beliefs about Ear and Hearing Health among Mothers of Young Children in a Rural Community in South India. Disability.
CBR \& Inclusive Development, 25(4), 119-135. doi: doi:http://dx.doi.org/10.5463/dcid.v 25i4.328.

National Policy on Education. (1986, amended in 1992). Delhi: Ministery of Human Resource Development, Government of India Retrieved from

http://www.ncert.nic.in/oth_anoun/ npe86.pdf.

Nunes, T. (2004). Teaching mathematics to deaf children. London, England: Whurr Publishers, Ltd.

Nunes, T., \& Moreno, C. (1998). The development of mathematical skills, Is hearing impairment a cause of difficulties in learning mathematics? . In C. Donlan (Ed.), The development of mathematical skills. Hove, Britain: Psychology Press.

Nunes, T., \& Moreno, C. (2002). An intervention program for promoting deaf pupils' achievement in mathematics. Journal of Deaf Studies and Deaf Education, 7(2), 120-133. doi: $10.1093 /$ deafed/7.2.120

Pagliaro, M., \& Kritzer, L. (2013). The math gap: A description of the mathematics performance of preschool-aged deaf/hard-of-hearing children. Journal of Deaf Studies and Deaf Education, 18(2), 139-160.

doi: $10.1093 /$ deafed/ens070

Paranjape, S. (1998). Achievement of normal and hearing handicapped pupils at the end of the primary cycle. Disabilities and Impairments, 10(2), 73-86.

Pau, S. (1995). The deaf child and solving problems of arithmetic: The importance of comprehensive reading. American Annals of the Deaf, 140(3), 287-290. doi: 10.1353/aad.2012.0599

Powers, S., Gregory, S., \& Thoutenhoofd, E. D. (1999). The educational achievements of deaf children: A literature review executive summary. Deafness and Education International, 1(1), 19. doi: $10.1002 /$ dei.38

Stewart, D., \& Kluwin, T. (2001). Teaching deaf and hard-of-hearing students: Content, strategies, and curriculum. Boston, MA: Allyn \& Bacon.

Stipek, D. (2002). At what age should children enter kindergarten? A question for 
policy makers and parents. Social Policy Report, Giving Child and Youth Development Knowledge Away, 16(2), 3-17.

Swanwick, A., Oddy, A., \& Roper, T. (2005). Mathematics and deaf children: an exploration of barriers to success. Deafness and Education International, 7(1), 1-21.

Traxler, B. (2000). The Stanford Achievement Test, (9th ed.): National norming and performance standards for deaf and hard-of-hearing students. Journal of Deaf Studies and Deaf Education, 5, 337-348.

doi: $10.1093 /$ deafed/5.4.337

Wilson, H., \& Antablin, K. (1980). A picture identification task as an estimate of the word-recognition performance of nonverbal adults. Journal of Speech and Hearing Disorders, 45(2), 223238. doi: $10.1044 /$ jshd. 4502.223
Wood, J., Wood, A., \& Howarth, P. (1983). Mathematical abilities of deaf school-leavers. British Journal of Developmental Psychology, 1, 67-73. doi:10.1111/j.2044835X.1983.tb0054 4. $x$

Zarfaty, Y., Nunes, T., \& Bryant, P. (2004). The performance of young deaf children in spatial and temporal number tasks. Journal of Deaf Studies and Deaf Education, 9(3), 315-326. doi: 10.1093/deafed/enh034 